\title{
Causal surgery under a Markov blanket
}

Daniel Yon ${ }^{1}$ and Philip Robert Corlett ${ }^{2}$

1. Department of Psychological Sciences, Birkbeck, University of London. UK.

2. Department of Psychiatry, Yale University, USA.

Correspondence: d.yon@bbk.ac.uk

This paper is a commentary on Bruineberg, Dolega, Dewhurst and Baltieri (forthcoming). The Emperor's New Markov Blankets. Behavioral and Brain Sciences.

Preprint posted to PsyArXiv on $5^{\text {th }}$ Jan 2022.

\begin{abstract}
Bruineberg et al provide compelling clarity

on the roles Markov blankets could (and perhaps should) play in the study of life and mind. However, here we draw attention to a further role blankets might play: as a hypothesis about cognition itself. People and other animals may use blanket-like representations to model the boundary between themselves and their worlds.
\end{abstract}

\section{Main text}

In their impressive target article Bruineberg et al describe two radically different ways we can use Markov blankets. Pearl blankets are tools that allow scientists to identify (in)dependence between variables when modelling complex systems. In contrast, Friston blankets are tools philosophers may use to parse the world into internal and external states, distinguishing agents from the rest of their worlds.

We wholeheartedly agree that this distinction is important, but feel this dichotomy neglects a third possibility: blankets as a hypothesis about cognition itself. In this way of thinking, cognising creatures may use processes that approximate Bayesian modelling to track which states of the world depend on or are independent of their actions. In so doing, these creatures construct a cognitive blanket that captures their beliefs about what they can and cannot control.

This cognitive blanket hypothesis makes distinctive predictions about how agents estimate agency and control over their bodies and the world. Many have suggested that humans and other animals determine what they can control by tracking correlations between actions and outcomes (Dickinson \& Balleine, 1994; Yon et al., 2020). However, building a cognitive blanket - mapping causal dependencies between actions and states - allows an agent to entertain counterfactual scenarios and to intervene on the world to test connections implied by their model. This kind of hypothesis testing - evocatively dubbed 'causal surgery' (Pearl et al., 2016) - allows agents to refine beliefs about their own causal power by acting on the world in informative ways. 
Psychologists can test for cognitive blankets by investigating whether agents are sensitive to counterfactual information and engage in 'causal surgery' to test what they can and cannot control. In humans, there is some evidence of sensitivity to counterfactual information we feel a greater sense of control when we believe we could have acted differently and this could have altered outcomes (Kulakova et al., 2017). There is also tentative evidence that human agents perform exploratory actions when judging control over events in the external world (Wen et al., 2020). This kind of exploration could be a hallmark of 'causal surgery' that tests hypotheses about our influence. However, it is also possible that apparently exploratory behaviour emerges from noise in decision and action systems (Findling et al., 2019). Targeted tests are thus needed to establish whether humans engage in genuine causal surgery when estimating control - possibly by determining whether explorations about control depend on the agent's uncertainty about action-outcome relationships.

The same tests could also be applied by comparative cognitive scientists. It has long been debated how far nonhuman animals represent their behaviour as 'causes' of environmental changes (Penn \& Povinelli, 2007). In our way of thinking, empirical evidence of causal surgery in different species would suggest the animal is constructing a cognitive blanket- testing hypotheses about how action and outcome connect. As with humans, it would be important to distinguish uncertainty-driven hypothesis testing in animals from blind exploration. Such efforts could exploit apparent signatures of 'confidence' detectable in animals (Kepecs et al., 2008), or could investigate how animals respond to different varieties of environmental uncertainty (Yon \& Frith, 2021). For instance, if a creature's exploratory behaviour responds to volatility in action-outcome relationships, this may be indicative of causal surgery: the active probing of the agent's blanketlike model to test what they can and cannot influence.

Furthermore, cognitive blankets could illuminate the disturbances of action awareness that occur in psychiatric illness. Patients with psychosis often develop delusions about action and control: they claim to control things they objectively cannot (grandiosity) and deny controlling some actions they have genuinely authored (passivity; Frith et al., 2000). These strange beliefs might arise from a disordered blanket that draws the boundary between world and agent in an unusual way (much like that depicted in Bruineberg et al Fig 7c). If intervention and exploration are essential ingredients in building up an accurate cognitive blanket, it may be fruitful for clinical scientists to investigate processes of causal surgery in psychosis. If these patients are less likely 
to intervene on the world to test what they can control, unusual beliefs about the self and the world may persist unchecked. Indeed, one could speculate that a vicious cycle obtains in psychosis, where negative symptoms dampening the drive to act (e.g., apathy, catatonia) rob patients of action-outcome experiences that could challenge positive symptoms (i.e., delusions about action; see Bortolotti \& Broome, 2012; Corlett et al., 2016).We note with interest the role that dopamine signalling appears to play in learning, confidence, causal inference, and their derangement in psychosis-like states (Redgrave \& Gurney, 2006; Schmack et al., 2021; Sharpe et al., 2017).

Our third way of thinking about blankets as representations in the heads of agents - departs from both Friston and Pearl blankets. Even if Friston blankets cannot pick out the objective boundaries between agents and their worlds, blanket-like computations may still be the processes by which some creatures (suboptimally) identify where these boundaries lie.

Moreover, the ability of scientists to model an agent using Pearl blankets cannot tell us whether the agent uses a cognitive blanket to model itself. For example, creatures that do not build a cognitive blanket may rely on simple, lean psychological processes like associative learning to navigate their environments (i.e.., without building a causal graph). However, these simpler psychological processes are only adaptive because they also gear creatures into the causal structure of their environments (Papineau \& Heyes, 2006). Simple creatures may thus be well modelled by Pearl blankets, even if they do not have a cognitive blanket of their own.

In conclusion, Bruineberg et al provide an important perspective on how scientists and philosophers should use Markov blankets to describe the boundaries between agents and their worlds. However, it is also important to consider (and test) whether blanket-like representations are at the heart of how agents construct these boundaries in their own minds.

\section{References}

Bortolotti, L., \& Broome, M. R. (2012). Affective dimensions of the phenomenon of double bookkeeping in delusions. Emotion Review, 4(2), 187-191. https://doi.org/10.1177/175407391143 0115

Corlett, P. R., Honey, G. D., \& Fletcher, P. C. (2016). Prediction error, ketamine and psychosis: an updated model. Journal of Psychopharmacology, 30(11), 1145-1155. https://doi.org/10.1177/026988111665 0087

Dickinson, A., \& Balleine, B. (1994). Motivational control of goal-directed action. Animal Learning \& Behavior, 22(1), 1-18. https://doi.org/10.3758/BF03199951

Findling, C., Skvortsova, V., Dromnelle, R., Palminteri, S., \& Wyart, V. (2019). Computational noise in reward-guided learning drives behavioral variability in volatile environments. Nature Neuroscience, 22(12), 2066-2077. https://doi.org/10.1038/s41593-0190518-9 
Frith, C. D., Blakemore, S. J., \& Wolpert, D. M. (2000). Abnormalities in the awareness and control of action. Philosophical Transactions of the Royal Society of London. Series B, Biological Sciences, 355(1404), 17711788.

https://doi.org/10.1098/rstb.2000.0734

Kepecs, A., Uchida, N., Zariwala, H. A., \& Mainen, Z. F. (2008). Neural correlates, computation and behavioural impact of decision confidence. Nature, 455(7210), $227-$ 231. https://doi.org/10.1038/nature07200

Kulakova, E., Khalighinejad, N., \& Haggard, P. (2017). I could have done otherwise: Availability of counterfactual comparisons informs the sense of agency. Consciousness and Cognition, 49, 237-244. https://doi.org/10.1016/j.concog.2017. 01.013

Papineau, D., \& Heyes, C. (2006). Rational or associative? Imitation in Japanese Quail. In M. Nudds \& S. Hurley (Eds.) Rational Animals. Oxford University Press.

Pearl, J., Glymour, M., \& Jewell, N. P. (2016). Causal inference in statistics: $A$ primer. John Wiley \& Sons.

Penn, D. C., \& Povinelli, D. J. (2007). Causal cognition in human and nonhuman animals: A comparative, critical review. Annual Review of Psychology, 58, 97-118.

https://doi.org/10.1146/annurev.psych. 58.110405 .085555
Redgrave, P., \& Gurney, K. (2006). The shortlatency dopamine signal: A role in discovering novel actions? Nature Reviews. Neuroscience, 7(12), 967975. https://doi.org/10.1038/nrn2022

Schmack, K., Bosc, M., Ott, T., Sturgill, J. F., \& Kepecs, A. (2021). Striatal dopamine mediates hallucination-like perception in mice. Science (New York, N.Y.), 372(6537), eabf4740. https://doi.org/10.1126/science.abf474 0

Sharpe, M. J., Chang, C. Y., Liu, M. A., Batchelor, H. M., Mueller, L. E., Jones, J. L., Niv, Y., \& Schoenbaum, G. (2017). Dopamine transients are sufficient and necessary for acquisition of model-based associations. Nature Neuroscience, 20(5), 735-742. https://doi.org/10.1038/nn.4538

Wen, W., Shibata, H., Ohata, R., Yamashita, A., Asama, H., \& Imamizu, H. (2020). The active sensing of control difference. iScience, 23(5), 101112. https://doi.org/10.1016/j.isci.2020.1011 12

Yon, D., Bunce, C., \& Press, C. (2020). Illusions of control without delusions of grandeur. Cognition, 205, 104429. https://doi.org/10.1016/j.cognition.202 0.104429

Yon, D., \& Frith, C. D. (2021). Precision and the Bayesian brain. Current Biology, 31(17), R1026-R1032. https://doi.org/10.1016/j.cub.2021.07.0 44 